\title{
Impact of timing of breastfeeding initiation on neonatal mortality in India
}

\author{
Deepika Phukan ${ }^{1 *}$, Mukesh Ranjan² and L. K. Dwivedi
}

\begin{abstract}
Background: Neonatal mortality defined as a death during the first 28 days of life and is the most critical phase of child survival. In spite of the strong evidence supporting immediate and long term health benefits of timely initiation of breastfeeding in India, only two-fifths (44\%) of children receive breastfeeding within $1 \mathrm{~h}$ of birth. This study aims to examine the role of a behavioral factor i.e., timing of initiation of breastfeeding on neonatal deaths.

Methods: Data from India Human Development Survey-II (IHDS-II), 2011-12, a nationally representative, large scale population-based dataset has been used. Sample Registration System (SRS) has been used to examine the rate of change in Neonatal Mortality Rates from the year 2011 to 2015. District Level Household \& Facility Survey (DLHS-4), 2012-2013 and Annual Health Survey(AHS), 2012-13 data have been used to show the district wise distribution of women who have breastfed their child within $1 \mathrm{~h}$ of birth. Population Attributable fraction has been computed using binary logistic regression model for various scenarios of breastfeeding within first hour of birth.

Results: Less than one fourth (21\%) of children were breastfed within $1 \mathrm{~h}$ of birth across the different districts of India, which varies from the lowest 15\% in Sarasvati of Uttar Pradesh state to the highest 94.6\% in Thiruvananthapuram of Kerala state. Findings suggest when women did not breastfeed their newborn within the $1 \mathrm{~h}$ after his birth, the odds of neonatal deaths were increased by nearly threefold (OR 2.93; $95 \% \mathrm{Cl} 1.89$, 4.53) in comparison with those neonates who have breastfed within $1 \mathrm{~h}$ of birth. Population Attributable Risk estimates that the risk of the neonatal deaths could be reduced to a maximum of $15 \%$ when all babies would expose to early breastfeeding from the present level of breastfeeding.

Conclusions: We found that timely initiation of breastfeeding is beneficial for child survival within the first 28 days of birth, including all causes of mortality. Therefore, efforts in formulating an effective policy focusing on early initiation of breastfeeding are needed.
\end{abstract}

Keywords: Breastfeeding, Neonatal mortality, IDHS-II, Binary logistic regression, Population attributable risk

\section{Background}

Globally, around 5.6 million children died before reaching their fifth birthday, of those, 2.6 million (or $46 \%$ ) died in the first 30 days of life [1]. Approximately 7000 newborns died every day, most of which occurred within first 7 days after birth, with about 1 million dying on the first day and close to 1 million dying within the next 6 days in 2016 [2]. Most of the neonates died in Southern Asia (39\%), followed by

\footnotetext{
* Correspondence: deephukan93@gmail.com

${ }^{1}$ Department of Public Health and Mortality Studies, International Institute for Population Sciences, Mumbai, Maharashtra 400088, India

Full list of author information is available at the end of the article
}

sub-Saharan Africa (38\%). Half of all newborn deaths occurred in the following five countries: India, Pakistan, Nigeria, the Democratic Republic of the Congo and Ethiopia [1]. Over the past 25 years, the age under-five mortality rate dropped from 93 deaths per 1000 live births in 1990 to 41 in 2016. In India, in the year 2015, infant mortality accounts for 37 infant deaths per 1000 live births, of which $67.8 \%$ infants (25 per 1000 live births) died in the first month of births [3]. In 2013, India recorded the highest absolute number of neonatal deaths of any country, nearly 0.75 million [4]. Despite a significant change in

(c) The Author(s). 2018 Open Access This article is distributed under the terms of the Creative Commons Attribution 4.0 International License (http://creativecommons.org/licenses/by/4.0/), which permits unrestricted use, distribution, and 
neonatal mortality over the years, progress has been inadequate towards achieving Millennium Development Goal 4 (MDG-4) [5]. In 2015, the Sustainable Development Goals (SDGs) have been introduced, seeking to achieve all the goals by 2030. Goal 3 of the Sustainable Development (SDG 3) is focused on promoting MDG-4 to reduce the under-five mortality by two thirds, between 1990 and 2015 and will continue beyond 2015, until neonatal mortality is at least as low as 12 per 1000 live births and under-5 mortality to at least as low as 25 per 1000 live births [6].

Various factors can effectively reduce neonatal mortality to greater levels, early initiation of breastfeeding is one of them and it has benefits for survival and beyond. The World Health Organization (WHO) has recommended that all neonates to be breastfed within $1 \mathrm{~h}$ of birth. The deleterious effects of infections related infant deaths can be prevented by early initiation of breastfeeding (or human milk feeding) and exclusive breastfeeding which is the easiest, cost-effective and life-saving intervention for the health of a newborn [7].

Early initiation of breastfeeding and exclusive breastfeeding for the first 6 months of life prevents around 20\% newborn deaths and 13\% under-five deaths [8]. It can also reduce mortality due to neonatal infections (sepsis, pneumonia, tetanus, and diarrhea) [9] which contribute $36 \%$ in neonatal deaths from all causes, and preterm birth an additional 27\% [10]. In spite of the strong evidence supporting immediate and long term health benefits, early initiation of breastfeeding in South Asia remains low with varying rate with $36.4 \%$ in India, $24 \%$ in Bangladesh and $8.5 \%$ in Pakistan [11-13]. In India, only $65 \%$ of children are exclusively breastfed for the first 6 months and $45 \%$ of children receive breastfeeding within $1 \mathrm{~h}$ of birth, though breastfeeding is one of the most important interventions of child survival [14]. In the year of 2016, the Government of India launched the National Breastfeeding Promotion Programme MAA (mothers' absolute affection) to ensure adequate awareness is generated among the masses, especially mothers, on the benefits of breastfeeding. The Programme will be implemented at three levels: Macro level through mass media; meso level in health facilities and micro level at communities [15].

Prior studies have shown that early initiation of breastfeeding is associated with a lower risk of neonatal mortality [16-19]. It is found that globally, only half of newborn babies are breastfed during their first hour of birth, despite strong evidence of nutritional and immunological benefits of early initiation in reducing neonatal mortality and morbidity $[18,20,21]$. The first milk (colostrum) contains bioactive immune factors which protect a neonate against a variety of infections and allergic diseases [22]. A recent systematic review of the literature based on 25 studies from seven countries in South Asia, revealed that early initiation of breastfeeding is predominately associated with socioeconomic, health related and individual factors, [23] and that insufficient attention is afforded to intrapartum and neonatal characteristics.

A few studies in India have examined associations between timing initiation of breastfeeding and neonatal mortality in different communities [24, 25]. There is a need for a national level study as it is important to examine the association between timing of initiation of breastfeeding and neonatal mortality nationally. The present study investigates the role of timing of initiation of breastfeeding in improving neonatal survival using a nationally representative large scale population-based dataset in India. In order to achieve the Sustainable Developmental Goals within stipulated time, we need to emphasize on the evidence-based conclusion regarding the linkages between timing of breastfeeding and neonatal mortality reduction as there is an urgent need to improve breastfeeding practices in India.

\section{Methods}

The India Human Development Survey-II (IHDS-II), 2011-12, has been used for the present analysis, which is a nationally representative and multi-topic survey of 42,152 households in 1503 villages and 971 urban neighborhoods across India. Most of these households had been interviewed for IHDS-I (2005). Both surveys cover all states and union territories of India with the exception of Andaman/Nicobar and Lakshadweep. Sample Registration System (SRS) dataset is used to see the rate of change in NMR from the year 2011 to 2015. District Level Household \& Facility Survey (DLHS-4), 2012-2013 and AHS (Annual Health Survey), 2012-13 state data have been used to show the district wise distribution of women who have breastfed their child within $1 \mathrm{~h}$ of birth.

\section{Definition of variables Outcome variable}

In the present analysis, neonatal mortality was taken as the outcome variable and coded as "0" for non-occurrence of neonatal death and " 1 " for occurrence of neonatal death. The analysis is restricted only for the last live births preceding the survey i.e. births since January 2005. A total of 37,350 births were recorded as last births in IHDS-II, 2011-12. Of a total live births, 340 children died before the completion of 28 days after birth.

\section{Exposure variables}

The independent variables for the study were divided into community, household, and maternal and child level 


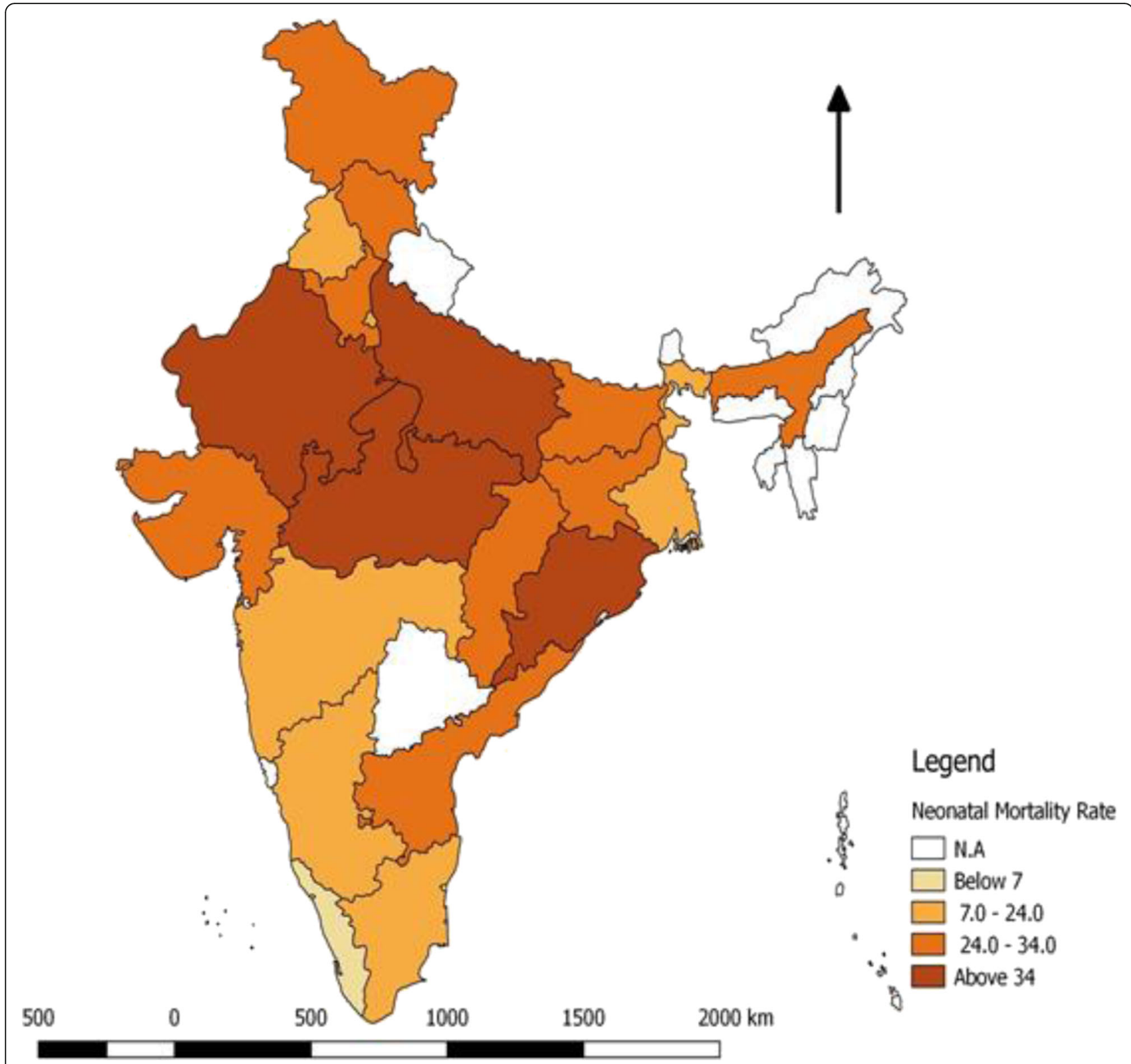

Fig. 1 State wise Distribution of Neonatal Mortality Rate in India, 2011

variables. Initiation of breastfeeding is computed from the question that "how long after birth, the mother first put her child to the breast". Early breastfeeding defined as a mother who put her child to the breast in less than an hour of his/her birth. The community level factors were state Regions and Place of residence (Rural/Urban). The data are available for all states and union territories of India with the exception of Andaman/Nicobar and Lakshadweep. The states were subdivided into five board regions as 1) North Region: Jammu \& Kashmir, Himachal Pradesh, Punjab, Chandigarh, Uttarakhand, Haryana, Delhi, Uttar Pradesh, 2) West Region: Rajasthan, Gujarat, Daman
\& Diu, Dadar and Nagar Haveli, Maharashtra, 3) South Region: Andhra Pradesh, Karnataka, Goa, Kerala, Tamil Nadu, Puducherry, 4) Central Region: Chhattisgarh, Madhya Pradesh, 5) East Region: Bihar, Jharkhand, Odisha, West Bengal, Arunachal Pradesh, Manipur, Meghalaya, Mizoram, Nagaland, Tripura, Sikkim. As established in literature, the household level variables were Religion (Hindu/Muslim/Others), Caste (Scheduled Tribe/Scheduled Caste/Others), and Wealth Quintile. The wealth quintile was constructed from the total income of the household. It was categorized into five quintiles (Poorest/ Poorer/ Middle/Richer and Richest). The maternal level 


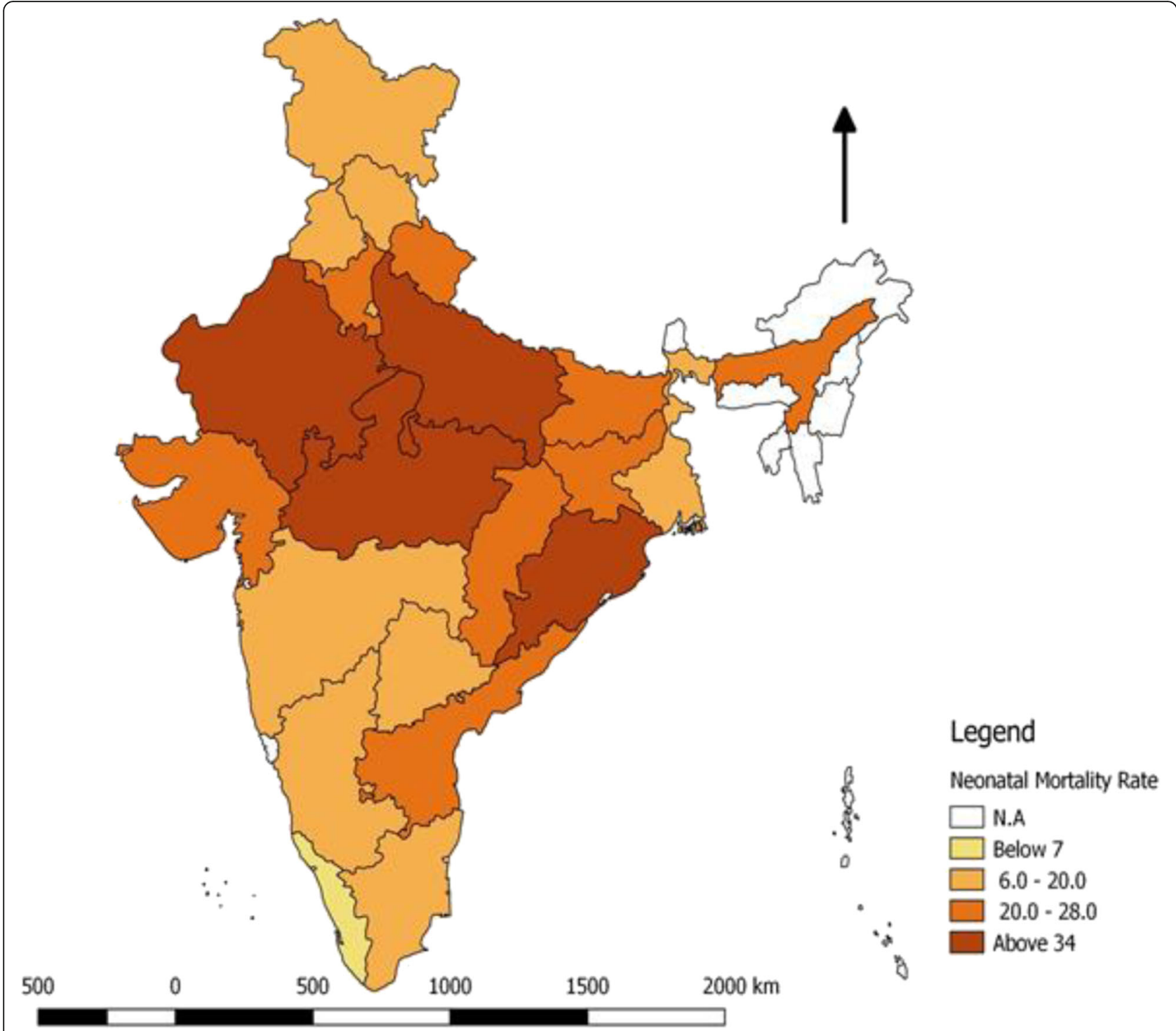

Fig. 2 State wise Distribution of Neonatal Mortality Rate in India, 2015

factors involved- Mother's age, Mother's education and Body Mass Index (BMI). The information was available in continuous which were converted into categorical variables with Mother's age (15-24/25-34/35+), Mother's education (No education/Primary/Secondary/Higher) and BMI (Underweight/ Normal/ Overweight /Obese). Child level variables like birth size (Large/Average/Small/ Very Small), Birth order (1/2-4/5+) and sex of the child (Boy/Girl) included in the model as dummies.

\section{Statistical analysis}

Univariate, Bivariate and Multivariate analysis were used in the present study. At the univariate level, Maps were generated by using Arc-GIS (version 10.5) and Geo Da (1.12 version) software. The bivariate analysis examined the relationship between the selected community, household, maternal and child level factors and neonatal deaths. At the Multivariate Analysis, Binary Logistic Regression Model has been used. Population Attributable Risk (PAR) has been calculated post estimated after multivariate logistic regression model. STATA 14 has been used for the statistical analysis.

\section{Results}

Figures 1 and 2 show the State Wise Neonatal Mortality rates (NMR) in the year of 2011 and 2015. In 2011, six of the 22 states had an NMR of more than 30 per 1000 live births, which is the threshold level of Millennium Development Goal 4 for Neonatal Mortality Rate. By 2015, only three states had an NMR more than 30 .

From the Fig. 3, we have seen the district wise prevalence of breastfeeding within $1 \mathrm{~h}$ of birth. The spatial 


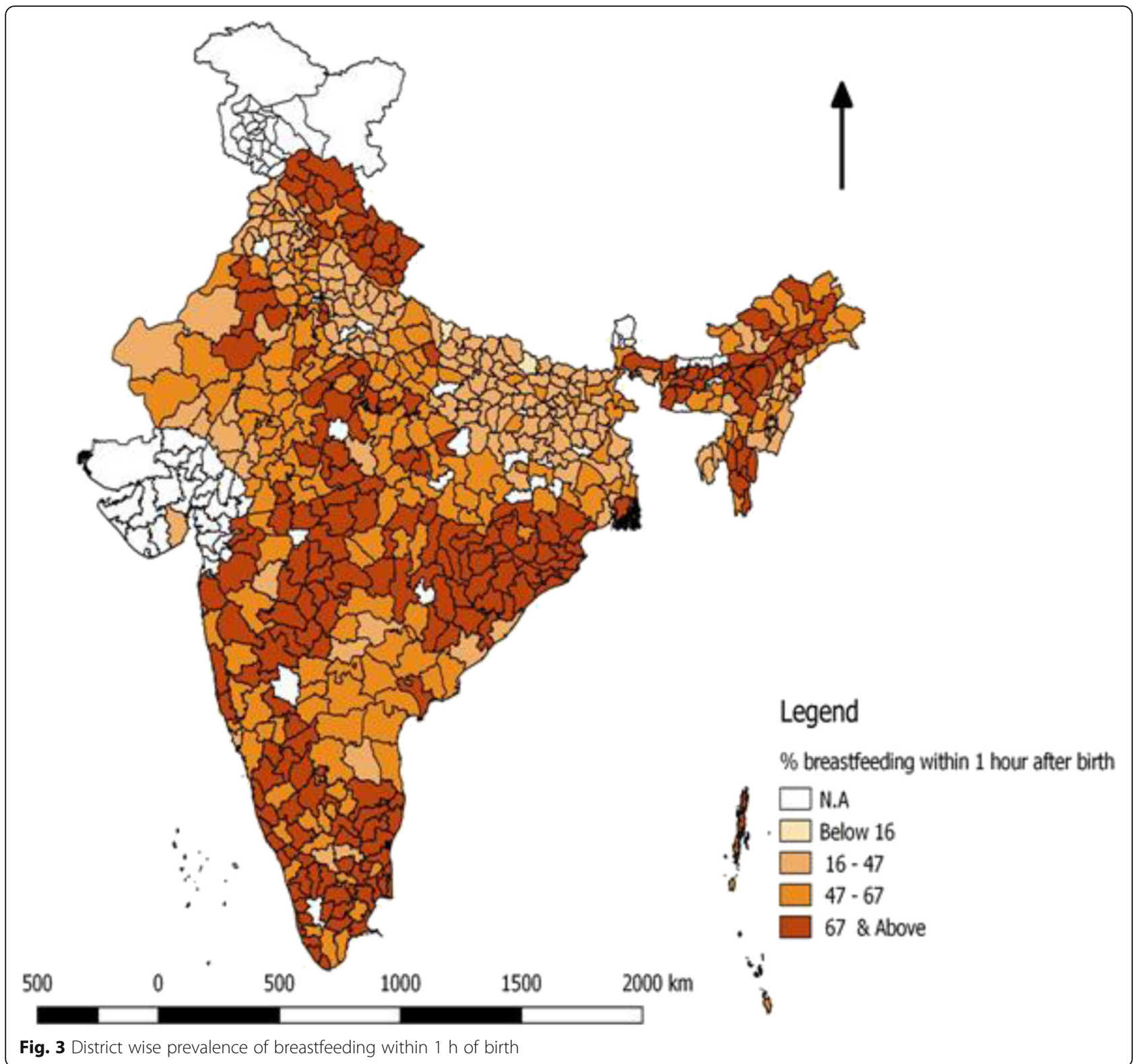

variation showed less than $40 \%$ of women were practicing breastfeeding their babies within $1 \mathrm{~h}$ of birth, in some districts of Rajasthan, Punjab, Haryana, Bihar, Uttar Pradesh and North-East. One of the notable feature that emerges from the map is that many districts where the prevalence of practicing breastfeeding is low, lies mostly in Bihar and distributed uniformly across the state.

Table 1 gives the total number and percentage distribution of live births in accordance with the background characteristics. There were only $21 \%$ live births that have breastfed within the $1 \mathrm{~h}$ of birth. A majority of babies lived in rural areas, whereas more than three-fourths were Hindu dominant households and belong to Other
Backward classes and Schedule tribes/caste. Maternal characteristics showed most of the babies were born to mothers in the age groups between 25 and 34 years. Only $11 \%$ of mothers had completed higher education. Less than half of the mothers were illiterate. Of the total number of mothers, only $3 \%$ were obese and more than half belonged to normal BMI (56.83\%). By examining the birth size of the babies, Table 1 depicts that almost $76 \%$ of babies were of average size at birth. The data shows an equivalent distribution of boys and girl across the nation.

In Table 2, odds ratios were given with 95\% of confidence interval after adjusting the covariates. If a woman did not breastfeed their newborn within $1 \mathrm{~h}$ after his/her 
Table 1 Distribution of neonatal deaths based on selected characteristics, India IHDS-II, 2011-12

\begin{tabular}{|c|c|c|c|c|c|}
\hline Variables & Live births (\%) & $N=37,350$ & Variables & Live births (\%) & $N=37,350$ \\
\hline Initiation of breastfeeding & & & Infant level factors & & \\
\hline Early & 21.1 & 7881 & Birth size & & \\
\hline Delayed & 78.9 & 29,477 & Large & 8.16 & 2927 \\
\hline Community level factors & & & Average & 75.53 & 27,093 \\
\hline Interstate region & & & Small & 14.47 & 5189 \\
\hline North & 32.62 & 12,185 & Very Small & 1.84 & 661 \\
\hline West & 18.58 & 6940 & Birth order & & \\
\hline South & 14.13 & 5277 & 1st order & 10.5 & 14,244 \\
\hline Central & 12.43 & 4644 & 2-4 order & 61.12 & 19,216 \\
\hline East & 22.25 & 8312 & $5+$ order & 28.38 & 3890 \\
\hline Place of residence & & & Sex of the child & & \\
\hline Rural & 73.34 & 27,399 & Boy & 49.39 & 18,446 \\
\hline Urban & 26.66 & 9959 & Girl & 50.61 & 18,904 \\
\hline
\end{tabular}

Religion

Hindu

Muslim

76.56

28,602

Others

18.88

7055

1701

Caste

General

$\mathrm{OBC}$

$\mathrm{ST} / \mathrm{SC}$

4.55

24.05

8986

15,523

12,849

Household Income

Poorest

17.93

6664

Poorer

18.54

Middle

20.34

Richer

Richest

21.33

21.86

Maternal level factors

Mother's age

$$
\text { 15-24 }
$$

25-34

$35+$

Women's education

No Education

Primary

Secondary

Higher

13.87

57.94

28.19

5181

21,647

10,530

16,441

2366

14,299

4242

BMI

Underweight

Normal

Overweight

Obese
44.02

38.29

11.36

28.36

56.83

11.63

3.17
Table 1 Distribution of neonatal deaths based on selected characteristics, India IHDS-II, 2011-12 (Continued)

birth then the odds of neonatal mortality is increased four (OR 3.54; 95\% CI 2.34, 5.38) times compared to those neonates who have breastfed within $1 \mathrm{~h}$ of birth. Once controlling for all the community and household level variables in Model I, the risk was still significant. There was a significant difference in neonatal mortality between interstate regions. The odds of neonatal mortality are decreased by $40 \%$ (OR 0.60 ; $95 \%$ CI $0.42,0.86$ ) for the West region as compared to the Northern region. Variation can also be seen in the Northern and Southern region; neonates were $52 \%$ (OR 0.48 ; 95\% CI $0.30,0.75$ ) less likely to die in the South than the North region. In the case of wealth quintile, neonates who belonged to the richest family has $48 \%$ (OR 0.52 ; $95 \%$ CI $0.35,0.77$ ) lower risk than those from the poorest family. When we add maternal and child level factors to Model II, Model III result showed that as the age of mother increases, neonatal deaths decreased. If a woman belongs to age $25-34$, the odds of neonatal mortality is decreased by $46 \%$ (OR 0.54; 95\% CI 0.39, 0.76) than those women who belong to age 15-24, further odds of neonatal mortality decreased to $49 \%$ (OR $0.51 ; 95 \%$ CI $0.33,0.97$ ) for the women belonging 35 years and above. Education levels of the mother also have a significant effect on neonatal mortality. Higher educated mothers have experienced less neonatal deaths than illiterate mothers. The expected odds of neonatal deaths is three times (OR 3.27; $95 \%$ CI $1.69,6.34$ ) higher for very small size babies than large size babies at birth. Neonatal death is decreased by $56 \%$ (OR 0.46; 95\% CI 0.32, 0.67) for higher birth order children, and by $26 \%$ (OR 0.74; $95 \%$ CI 0.59 , 0.94 ) for a girl child compared to a boy child.

Table 3 provide the post estimated value of logit model for Population Attributable Fraction (PAF) for different 
Table 2 Risks of neonatal mortality according to time of initiation of breastfeeding, community level, household level, maternal and child level variables, IHDS-2, 2011-12

\begin{tabular}{|c|c|c|c|}
\hline Variables & Model I, OR (95\% Cl) & Model II, OR (95\% Cl) & Model III, OR (95\% Cl) \\
\hline \multicolumn{4}{|c|}{ Initiation of breastfeeding } \\
\hline Early ${ }^{\oplus}$ & 1 & 1 & 1 \\
\hline Delayed & $3.54(2.34,5.38)^{* *}$ & $3.49(2.29,5.33)^{* *}$ & $2.93(1.89,4.53)^{* *}$ \\
\hline \multicolumn{4}{|c|}{ Community level factors } \\
\hline \multicolumn{4}{|l|}{ Interstate region } \\
\hline North ${ }^{\circledast}$ & & 1 & 1 \\
\hline West & - & $0.60(0.42,0.86)^{*}$ & $0.61(0.41,0.89)^{*}$ \\
\hline South & - & $0.48(0.30,0.75)^{* *}$ & $0.29(0.16,0.53)^{* *}$ \\
\hline Central & - & $0.92(0.66,1.29)$ & $1.02(0.72,1.44)$ \\
\hline East & - & $1.22(0.93,1.60)$ & $1.09(0.80,1.49)$ \\
\hline \multicolumn{4}{|l|}{ Place of residence } \\
\hline Rural $^{\circledast}$ & - & 1 & 1 \\
\hline Urban & - & $0.77(0.58,1.03)$ & $0.84(0.61,1.15)$ \\
\hline \multicolumn{4}{|c|}{ Household level factors } \\
\hline \multicolumn{4}{|l|}{ Religion } \\
\hline$H_{i n d u^{\oplus}}$ & - & 1 & 1 \\
\hline Muslims & - & $1.128(0.83,1.53)$ & $0.88(0.61,1.26)$ \\
\hline Others & - & $0.93(0.54,1.62)$ & $1.21(0.69,2.13)$ \\
\hline \multicolumn{4}{|l|}{ Caste } \\
\hline General $^{\circledast}$ & - & 1 & 1 \\
\hline OBC & - & $1.13(0.83,1.52)$ & $1.36(0.95,1.92)$ \\
\hline ST/SC & - & $1.31(0.94,1.81)$ & $1.45(1.00,2.12)$ \\
\hline \multicolumn{4}{|l|}{ Wealth quintile } \\
\hline Poorest & - & 1 & 1 \\
\hline Poorer & - & $0.71(0.52,0.99)$ & $0.86(0.60,1.23)$ \\
\hline Middle & - & $0.87(0.64,1.19)$ & $1.02(0.72,1.45)$ \\
\hline Richer & - & $0.76(0.55,1.07)$ & $0.89(0.62,1.29)$ \\
\hline Richest & - & $0.52(0.35,0.77)^{* *}$ & $0.67(0.44,1.04)$ \\
\hline \multicolumn{4}{|l|}{ Maternal level factors } \\
\hline \multicolumn{4}{|l|}{ Mother's age } \\
\hline $15-24^{\oplus}$ & - & - & 1 \\
\hline $25-34$ & - & - & $0.54(0.39,0.76)^{* *}$ \\
\hline $35+$ & - & - & $0.51(0.33,0.97)^{*}$ \\
\hline \multicolumn{4}{|c|}{ Women's education } \\
\hline No education ${ }^{\circledast}$ & - & - & 1 \\
\hline Primary & - & - & $0.46(0.23,0.91)^{*}$ \\
\hline Secondary & - & - & $0.97(0.73,1.29)$ \\
\hline Higher & - & - & $0.55(0.31,0.99)^{*}$ \\
\hline \multicolumn{4}{|l|}{ BMl } \\
\hline Underweight ${ }^{\oplus}$ & - & - & 1 \\
\hline Normal & - & - & $0.89(0.68,1.16)$ \\
\hline Overweight & - & - & $1.37(0.91,2.06)$ \\
\hline Obese & - & - & $1.73(0.90,3.30)$ \\
\hline
\end{tabular}


Table 2 Risks of neonatal mortality according to time of initiation of breastfeeding, community level, household level, maternal and child level variables, IHDS-2, 2011-12 (Continued)

\begin{tabular}{|c|c|c|c|}
\hline Variables & Model I, OR (95\% Cl) & Model II, OR (95\% Cl) & Model III, OR (95\% Cl) \\
\hline \multicolumn{4}{|c|}{ Infant level factors } \\
\hline \multicolumn{4}{|l|}{ Birth size } \\
\hline $\operatorname{Large}^{\oplus}$ & - & - & 1 \\
\hline Average & - & - & $0.92(0.57,1.47)$ \\
\hline Small & - & - & $1.45(0.86,2.43)$ \\
\hline Very Small & - & - & $3.27(1.69,6.34)^{* *}$ \\
\hline \multicolumn{4}{|l|}{ Birth order } \\
\hline 1st order ${ }^{\circledast}$ & - & - & 1 \\
\hline 2-4 order & - & - & $0.46(0.32,0.67)^{* *}$ \\
\hline $5+$ order & - & - & $0.71(0.45,1.14)$ \\
\hline \multicolumn{4}{|c|}{ Sex of the child } \\
\hline Boy ${ }^{\oplus}$ & - & - & 1 \\
\hline Girl & - & - & $0.74(0.59,0.94)^{*}$ \\
\hline
\end{tabular}

(') Reference Category, ${ }^{* *} p<0.01,{ }^{*} p<0.05$

situations of breastfeeding. In the Table 3, the Population Attributable Risk was estimated for the situation when all babies are exposed to breastfeeding. Scenario 0 represents the baseline scenario which is an overall predicted probability of neonatal deaths at adjusted level while, Scenario 1 (fantasy scenario) represents the predicted probability of neonatal deaths when all babies are exposed to breastfeeding and other factors in the model are adjusted. In this study, we found PAF to be -0.15 which indicates that when all babies are exposed to early breastfeeding, the risk of the neonatal deaths could be reduced to a maximum of $15 \%$ from the present level. Similarly, in Table 4 we have chosen a scenario (Scenario 1) when all the babies were not breastfed within the first hour of birth We found that in this extreme worst situation, the risk of neonatal deaths will increase to the level of $60 \%$.

\section{Discussion}

The present study supports the protective effect of early breastfeeding initiation on death within the first 28 days, including all-cause mortality. Wide interstate and intrastate variations exist in neonatal mortality across the country [26]. The present study also depicts that there is a north-south variation seen in neonatal deaths. It is

Table 3 Population Attributable Risk when all babies are exposed to breastfeeding

\begin{tabular}{llll}
\hline & Mean/Ratio & {$[95 \% \mathrm{Cl}]$} & \\
\hline Scenario_0 & $0.008^{* *}$ & 0.007 & 0.009 \\
Scenario_1 & $0.009^{* *}$ & 0.008 & 0.011 \\
PUF & $1.151^{* *}$ & 1.108 & 1.196 \\
PAF & $-0.151^{* *}$ & -0.196 & -0.108 \\
${ }^{* *} p<0.01$ & & &
\end{tabular}

clear from the maps that northern part of India is more vulnerable to neonatal mortality than southern part of India. Neonatal deaths can be prevented or reduced by early initiation of breastfeeding and exclusive breastfeeding [7]. There is a stark variation seen in children who have breastfed within $1 \mathrm{~h}$ of birth across the districts. The districts of Kerala, Tamil Nadu, Maharashtra, Odisha, Chhattisgarh, Madhya Pradesh, Himachal Pradesh, Uttarakhand and some districts of the North-East babies are more exposed to early initiation of breastfeeding, while babies from the districts of Bihar, Uttar Pradesh, Haryana, and Punjab are more exposed to delayed initiation of breastfeeding, where the rate of neonatal deaths are also high.

Newborn care immediately after the birth is vital since $40 \%$ of all neonatal deaths occur on the first day of life and 56\% during the first 3 days [27]. The timing of breastfeeding initiation is found to be the most significant risk factor which affects neonatal deaths [7]. Early initiation of exclusive breastfeeding serves as the starting point for a continuum of care for mother and newborn that can have long-lasting effects on health and development [28]. The findings of the present study resemble its predecessor. There was an odd of

Table 4 Population Attributable Risk when all babies are not exposed to breastfeeding

\begin{tabular}{llll}
\hline & Mean/Ratio & {$[95 \% \mathrm{Cl}]$} & \\
\hline Scenario_0 & $0.008^{* *}$ & 0.007 & 0.009 \\
Scenario_1 & $0.003^{* *}$ & 0.002 & 0.009 \\
PUF & $0.398^{* *}$ & 0.268 & 0.593 \\
PAF & $0.601^{* *}$ & 0.407 & 0.732 \\
${ }^{* *} p<0.01$ & & &
\end{tabular}

${ }^{* *} p<0.01$ 
3-fold increase in the risk of neonatal deaths if there was a delay in initiation of breastfeeding.

In India, there are wide disparities in mortality by caste, region, place of residence, and economic status, among other characteristics [29]. These variations are related to differences in wealth, nutrition, education, availability of health services, culture and gender equality status [30]. The literature suggests that infant mortality rates have been inversely related to socioeconomic status, and child mortality is higher among the low-income families than non-poor families [31], which is consistent with our study.

Maternal and child level determinants as the weight of neonate, gestational age, and age of mother play a major role in the neonate's survival [32]. Also, consistent with the earlier findings, maternal factors like mother's age and education were prominent factors in neonatal mortality. Along with the maternal characteristics, child level factors have a notable effect on neonatal mortality. Very small babies were more likely to die than larger babies, babies and males were more vulnerable to neonatal death than females.

It is also found that two-thirds of the incidence of neonatal mortality can be attributed to delayed breastfeeding i.e., out of the total population, $60 \%$ of the babies died within 1 month of their birth because of they were not breastfed within $1 \mathrm{~h}$. It has strong policy implications as we could reduce the risk of neonatal deaths to a great extent by giving them timely breastfeeding.

The limitations of the present study are that IHDS-II data were self-reported, as information on each outcome and determinants were collected retrospectively, there could be recall bias, that may have impact on results.

\section{Conclusions}

Though India has witnessed momentous changes in the infant health scenario over the years, the changes have not been uniform. Neonatal deaths are influenced by host of variables like community, household, maternal and infant level factors. The early initiation of breastfeeding can reduce the risk of neonatal deaths by odds of three times. So, these findings support the recommendations of early initiation of breastfeeding as an intervention to reduce neonatal mortality. The implementation of policies and pro-breastfeeding routines are the major recommended interventions to achieve SDGs to reduce neonatal mortality.

\footnotetext{
Abbreviations

AHS: Annual Health Survey; BMI: Body Mass Index; Cl: Confidence interval; DLHS: District Level Household \& Facility Survey; IHDS: The India Human Development Survey; IMR: Infant mortality rate; MDGs: Millennium Development Goals; NMR: Neonatal Mortality Rate; PAR: Population Attributable Risk; SDGs: Sustainable Development Goals; SRS: Sample Registration System; WHO: World Health Organization
}

\section{Availability of data and materials}

The IHDS-II dataset used during the current study are available in public domain from India Human Development Survey (https://ihds.umd.edu). SRS and AHS reports are available in the Census of India website (http:// www.censusindia.gov.in/2011-Common/Sample_Registration_System.html) or (http://www.censusindia.gov.in/2011-Common/AHSurvey.html). District Level Household \& Facility Survey (DLHS-4), 2012-2013 data is available in International Institute for Population Sciences (http://www.iipsindia.ac.in/) or http://rchiips.org/DLHS-4.html

\section{Authors' contributions}

DP and LKD conceptualized the paper and finalized the analysis plan; MR and DP analyzed the Dataset and generated the tables; DP prepared the first draft of the paper. All authors read and approved the final manuscript.

\section{Ethics approval and consent to participate}

Ethics approval and participant consent was not necessary as this study is based on secondary previously-published de-identified database IHDS-II, 2011-12. The IHDS-II survey received ethical reverence from the Ethics Review Committee of the National Council of Applied Economic Research, Delhi and the Institutional Review Board of the University of Maryland, College Park, USA. Participation of individuals in the survey was voluntary. Prior informed written consent was obtained from each respondent.

\section{Competing interests}

The authors declare that they have no competing interests.

\section{Publisher's Note}

Springer Nature remains neutral with regard to jurisdictional claims in published maps and institutional affiliations.

\section{Author details}

${ }^{1}$ Department of Public Health and Mortality Studies, International Institute for Population Sciences, Mumbai, Maharashtra 400088, India. ${ }^{2}$ Department of Mathematical Demography \& Statistics, International Institute for Population Sciences, Mumbai, Maharashtra 400088, India.

Received: 6 September 2017 Accepted: 10 May 2018

Published online: 03 July 2018

\section{References}

1. UNICEF: Levels \& Trends in Child Mortality, Estimates Developed by the UN Inter-agency Group for Child Mortality Estimation. New York: UNICEF; 2017.

2. World Health Organization (WHO). Global Health Observatory (GHO) data on Child mortality and causes of death; 2017. Available: http://www.who. int/gho/child_health/mortality/neonatal_text/en/.

3. Registrar General of India (RGI). Sample Registration System Statistical Report 2015. Available: http://www.censusindia.gov.in/vital_statistics/SRS_ Reports_2015.html.

4. Wardlaw T, Amouzou A, Velez L, Dwivedi A, Hug L. Committing to child survival: a promise renewed. Progress Report. 2014. Available: https://data. unicef.org/wp-content/uploads/2015/12/APR-2014-170ct14-web_194.pdf.

5. UNICEF: Levels \& Trends in Child Mortality, Estimates Developed by the UN Inter-agency Group for Child Mortality Estimation. New York: UNICEF; 2015.

6. United Nations. The UN Millennium Development Goals. 2015 Available: http://www.un.org/sustainabledevelopment/sustainabledevelopment-goals/.

7. World Health Organization (WHO). Early Initiation of breastfeeding: the key to survival and beyond: WHO Secretariat; 2010. p. 1-7. http://new.paho.org/ hq/dmdocuments/2010/Eight\%20Pager\%20English\%20FINAL.pdf.

8. Jones G, Steketee RW, Black RE, Bhutta ZA, Morris SS. Bellagio child survival study group. How many child deaths can we prevent this year? Lancet. 2003;362:65-71.

9. Mullany LC, Katz J, Li YM, Khatry SK, LeClerq SC, Darmstadt GL, Tielsch JM. Breast-feeding patterns, time to initiation, and mortality risk among newborns in southern Nepal. J Nutr. 2008;138:599-603.

10. Lawn J, Shibuya K, Stein C. No cry at birth: global estimates of intrapartum stillbirths and intrapartum-related neonatal deaths. Bull World Health Organ. 2005;83:409-17. 
11. Patel A, Banerjee A, Kaletwad A. Factors associated with prelacteal feeding and timely initiation of breastfeeding in hospital-delivered infants in India. J Hum Lact. 2013;29:572-8.

12. Haider R, Rasheed S, Sanghvi TG, Hassan N, Pachon H, Islam S, Jalal CS Breastfeeding in infancy: identifying the program-relevant issues in Bangladesh. Int Breastfeed J. 2010;5:21.

13. Hanif HM. Trends in breastfeeding and complementary feeding practices in Pakistan, 1990-2007. Int Breastfeed J. 2011;6:15.

14. Ministry of Women and Child Development. Rapid Survey on Children 2013-2014. India Factsheet. Provisional. Government of India. Available from: http://wcd.nic.in/sites/default/files/State\%20RSOC.pdf. Accessed 29 Aug 2015

15. Government of India. Ministry of Health and Family Welfare: National Breastfeeding Promotion Programme- MAA. 2016.

16. Debes AK, Kohli A, Walker N, Edmond K, Mullany LC. Time to initiation of breastfeeding and neonatal mortality and morbidity: a systematic review. BMC Public Health. 2013;13(Suppl 3):S19.

17. Berde AS, Yalcin SS. Determinants of early initiation of breastfeeding in Nigeria: a population-based study using the 2013 demographic and health survey data. BMC Pregnancy and Childbirth. 2016;16:32.

18. NEOVITA Study Group. Timing of initiation, patterns of breastfeeding, and infant survival: prospective analysis of pooled data from three randomised trials. Lancet Glob Health. 2016;4:e266-e275.

19. Lassi ZS, Middleton PF, Crowther C, Bhutta ZA. Interventions to improve neonatal health and later survival: an overview of systematic reviews. EBiomedicine. 2015;2:985-1000

20. Victora CG, Bahl R, Barros AJ, França GV, Horton S, Krasevec J, Murch S, Sankar MJ, Walker N, Rollins NC, Group TL. Breastfeeding in the 21st century: epidemiology, mechanisms, and lifelong effect. Lancet. 2016;387:475-90.

21. Khan J, Vesel L, Bahl R, Martines JC. Timing of breastfeeding initiation and exclusivity of breastfeeding during the first month of life: effects on neonatal mortality and morbidity a systematic review and meta-analysis. Matern Child Health J. 2015;19:468-79.

22. Chae A, Aitchison A, Day AS, Keenan Jl. Bovine colostrum demonstrates anti-inflammatory and antibacterial activity in in vitro models of intestinal inflammation and infection. J Funct Foods. 2017;28:293-8.

23. Sharma IK, Byrne A. Early initiation of breastfeeding: a systematic literature review of factor and barriers in South Asia. Int Breastfeed J. 2016;11:17.

24. Bamji MS, Murthy PV, Williams L, Rao MV. Maternal nutritional status \& practices \& perinatal, neonatal mortality in rural Andhra Pradesh, India. Indian J Med Res. 2008;127:144.

25. Garcia CR, Mullany LC, Rahmathullah L, Katz J, Thulasiraj RD, Sheeladevi S, Coles C, Tielsch JM. Breast-feeding initiation time and neonatal mortality risk among newborns in South India. J Perinatol. 2011;31:397-403.

26. Saikia N, Shkolnikov VM, Jasilionis D, Chandrashekhar. Trends and subnational disparities in neonatal mortality in India from 1981 to 2011. Asian Popul Stud. 2016;12:88-107.

27. ICMR Young Infant Study Group. Age profile of neonatal deaths. Indian Pediatr. 2008;45:991.

28. Begum K, Dewey KG. Impact of early initiation of exclusive breastfeeding on newborn deaths. Alive and Thrive Technical Brief. 2010;1:99-109.

29. Ram U, Jha P, Ram F, Kumar K, Awasthi S, Shet A, Pader J, Nansukusa S, Kumar R. Neonatal, 1-59 month, and under-5 mortality in 597 Indian districts, 2001 to 2012: estimates from national demographic and mortality surveys. Lancet Glob Health. 2013;1:e219-26.

30. Bang AT, Paul VK, Reddy HM, Baitule SB. Why do neonates die in rural Gadchiroli, India? (part I): primary causes of death assigned by neonatologist based on prospectively observed records. J Perinatol. 2005;25:S29.

31. Edeme RK, Innocent Al, Okereke OS. Relationship between household income and child mortality in Nigeria. Am J Life Sci. 2014;2:1-2.

32. Kozuki N, Lee AC, Silveira MF, Sania A, Vogel JP, Adair L, et al. The associations of parity and maternal age with small-for gestational-age, preterm, and neonatal and infant mortality: a meta-analysis. BMC Public Health. 2013;13(Suppl 3):S2

\section{Ready to submit your research? Choose BMC and benefit from:}

- fast, convenient online submission

- thorough peer review by experienced researchers in your field

- rapid publication on acceptance

- support for research data, including large and complex data types

- gold Open Access which fosters wider collaboration and increased citations

- maximum visibility for your research: over $100 \mathrm{M}$ website views per year

At BMC, research is always in progress.

Learn more biomedcentral.com/submissions 